9. Lakoff, G., Johnson, M. (1980). Metaphors We Live By. Chicago: University of Chicago Press [in English].

10. Mats, B. Küssner (2017). Shape, drawing and gesture: empirical studies of cross-modality. Music and shape. Edited by Daniel LeechWilkinson, Helen M. Prior. New York, NY: Oxford University Press (Series: Studies in musical performance as creative practice) [in English].

11. Yust, J. (2018). Organized time: rhythm, tonality, and form. New York, NY: Oxford University Press (Series: Oxford studies in music theory. Includes bibliographical references and index) [in English].

УДК 78.071.1

DOI https://doi.org/10.31723/2524-0447-2020-30-2-17

Александр Александрович Перепелица

ORCID: 0000-0001-5206-205X

кандидат искусствоведения,

и. о. доцента кафедры оперной подготовки

Одесской национальной музыкальной академии

имени А. В. Неждановой

o.perepl@gmail.com

\title{
ЭСТЕТИЗАЦИЯ ТРАГИЧЕСКОГО В КОНТЕКСТЕ СОВРЕМЕННОЙ МУЗЫКАЛЬНОЙ КУЛЬТУРЫ НА ПРИМЕРЕ КОНЦЕРТА-ДРАМЫ № 2 К. ЦЕПКОЛЕНКО
}

Категория трагического как культурологическая проблема приобретает универсальную широту и может рассматриваться как одна из центральных в духовном опыте человека и человечества, а значит, анализ феномена трагического всегда актуален. Исследование феномена трагического представляет особый интерес в контексте творчества К.С. Цепколенко. Столкновение двух сил - жесткого неумолимого рока и феномена коллективной несгибаемой воли, твердости характера и жажды жкизни. Пять каденций, в которых фортепиано выступает в диалоге с одним из инструментов оркестра, раскрывают трагический путь борьбы и, в конце концов, торжества «светлых» сил. Каденции олицетворяют собой психологические состояния героев, и каждая из них становится рубежсом качественных изменений. Дуэты, которые в конце

(C) Перепелица А. А., 2020 
концерта соединяются в квинтет, олицетворяют собой силы величия человеческого духа и демонстрируют образеи противоборства силам стихии, рока, а партия оркестра олицетворяет собой стихии и трагические обстоятельства, которым противоборствует человек. Цель исследования - определить особенности прочтения жканрового канона трагического в рамках индивидуальной авторской интерпретации стилей К.С. Цепколенко. Методология исследования опирается на методы сравнительного, а также комплексно-системного анализа, рассматривающие произведение как составную часть целостной и многогранной культуры. Научная новизна работы определяется детерминацией исследования областью «Трагедия», направленной на малоизученное в этом отношении произведение К.С. Цепколенко. Новым представляется и ракурс исследования, направленный на обоснование драматической природы исследуемого произведения, а также принципов систематизации жанра трагедии. Выводы. Кониертный жанр в творчестве К.С. Цепколенко определяют контрастность, драматизм, множественность, диффузность, эксперимент. Это не строгое следование жканровому канону и не отрицание его законов. Композитор «отпускает жканр на свободу», полностью подчиняя его каноны идее, драматургической логике.

Ключевые слова: трагедия, трагедийный симфонизм, театрализаиия симфонизации.

Perepelytsia Oleksandr Oleksandrovych, Ph.D. (Arts), Acting Associate Professor at the Department of Opera Training of the Odessa National A. V. Nezhdanova Academy of Music

Aesthetization of the tragic in the context of modern musical culture on the example of Drama Concert No. 2 by K. Tsepkolenko's

The category of the tragic as a culturological problem acquires a universal breadth, and can be considered as one of the central categories in the spiritual experience of human and humanity, which means that the analysis of the phenomenon of the tragic is always relevant. The study of the phenomenon of the tragic is of particular interest in the context of the work of $K$. Tsepkolenko. The clash of two forces - a tough unforgiving fate and the phenomenon of collective unbending will, strength of character and thirst for life. Five cadences, where the piano is one of the instruments of the orchestra, reveal the tragic path of struggle and, in the end, the triumph of «light» forces. The cadences personify the psychological states of the characters, and each of them becomes a borderline of qualitative changes. The duets, which form a quintet at the end of the concert personify the forces of the greatness of the human spirit and demonstrate an example of confrontation with the forces of elements, fate, and the part of the orchestra - personifies the elements and tragic circumstances a person opposes. The purpose of the work is to determine the peculiarities of reading of the genre canon of the tragic within the framework of the individual author interpretation of the styles of $K$. Tsepkolenko. The research methodology is based on the methods of comparative, as well as complexsystemic analysis, which consider the piece as an integral part of a holistic and multifaceted culture. The scientific novelty of the work is determined by 
the study of the field of "Tragedy", aimed at the poorly studied in this respect work of K. Tsepkolenko. Also novel is the perspective of the research, aimed at substantiating the dramatic nature of the work under study as well as the principles of systematizing the tragedy genre. Conclusions. The concert genre in the work of $K$. Tsepkolenko, is determined by contrast, drama, multiplicity, diffuseness, experiment. This is not a strict adherence to the genre canon, and not a denial of its laws. The composer "sets the genre free", completely subordinating its canons to the idea, dramaturgic logic.

Key words: tragedy, tragic symphonism, theatricalization of symphonization.

Перепелиця Олександр Олександрович, кандидат мистецтвознавства, в. о. доцента кафедри оперної підготовки Одеської національної музичної академії імені А. В. Нежданової

Естетизація трагічного в контексті сучасної музичної культури на прикладі Концерту-драми № 2 К. Цепколенко

Категорія трагічного як культурологічна проблема набуває універсальної широти і може розглядатися як одна із центральних у духовному досвіді людини і людства, а значить, аналіз феномену трагічного завжди актуальний. Дослідження феномену трагічного представляє особливий інтерес у контексті творчості К.С. Цепколенко. Зіткнення двох сил - жорстокого невблаганного року і феномену колективної незламної волі, твердості характеру і жаги до життя. П'ять каденцій, в яких фортепіано виступає в діалозі з одним із інструментів оркестру, розкривають трагічний шлях боротьби $i$, врешті-решт, торжества «світлих» сил. Каденції уособлюють собою психологічні стани героїв, $i$ кожна з них стає кордоном якісних змін. Дуети, які в кінці концерту з'єднуються у квінтет, уособлюють собою сили величі людського духу $i$ демонструють зразок протиборства силам стихії, рока, а партія оркестру уособлює собою стихії та трагічні обставини, яким протистоїть людина. Мета роботи - визначення особливостей прочитання жканрового канону трагічного в рамках індивідуальної авторської інтерпретації стилів К.С. Цепколенко. Методологія дослідження спирається на методи порівняльного, а також комплексно-системного аналізу, які розглядають твір як складову частину иілісної і багатогранної культури. Наукова новизна роботи визначається детермінацією дослідження області «Трагедія», спрямованої на маловивчений у иьому відношенні твір К.С. Цепколенко. Новим є і ракурс дослідження, спрямований на обгрунтування драматичної природи досліджуваного твору, а також принципів систематизації жанру трагедії. Висновки. Основними принципами, на яких будується драматургія кониерту, є протиставлення трагедійності й лірики; концертний жсанр у творчості К.С. Цепколенко визначають контрастність, драматизм, множинність, диффузність, експеримент. Це не суворе дотримання жанрового канону й не заперечення його законів. Композитор «відпускає жанр на свободу», повністю підпорядковуючи його канони ідеї, драматургічній логіці.

Ключові слова: трагедія, трагедійний симфонізм, театралізація симфонізації. 
Актуальность темы исследования. Категория трагического зародилась в Древней Греции и с тех пор превратилась в неизменный атрибут человеческой культуры. Трагическое как культурологическая проблема приобретает универсальную широту и занимает одно из центральных мест в духовном опыте человека и человечества, а значит, анализ феномена трагического всегда актуален. Исследование феномена трагического представляет особый интерес в контексте творчества К.С. Цепколенко. Концертный стиль композитора своеобразен и отличается трагической направленностью, драматизмом, органичностью и единством замысла. Тип современного концерта, который создала К. Цепколенко, сочетает, казалось бы, несовместимые начала: концертный блеск, театральную рельефность тематизма, кинематографическую монтажность, неуёмную энергию и интимность, отстранённость лирики, погружение во внутренний мир, психологическую тонкость, драматичность и трагизм.

Цель исследования - определить особенности прочтения жанрового канона трагического в рамках индивидуальной авторской интерпретации концертного стиля К.С. Цепколенко.

Научная новизна работы определяется детерминацией исследования областью «Трагедия», направленной на малоизученное в этом отношении произведение К.С. Цепколенко. Новым представляется и ракурс исследования, направленный на обоснование драматической природы исследуемого произведения, а также принципов систематизации жанра трагедии.

Трагедия в своем поступательном развитии так или иначе приводит к смерти. Но смерть здесь - не конечная точка, которая обрывает жизнь, а, скорее, иная реальность, которая заставляет человека острее переживать всю прелесть и радость бытия. И не случайно, подчеркивая жертвенность во имя жизни, искусство породило такую разновидность трагического, как оптимистическая трагедия.

В трагедийном произведении, в борьбе, зачастую неравной, герой действует на пределе возможностей, выходя за границы, очерченные природой, превозмогая условности, руководствуясь высокими идеалами. Трагический герой прокладывает путь к будущему, он взрывает устоявшиеся границы, он всегда на переднем крае борьбы человечества, на его плечи ложатся наибольшие трудности. Несмотря на гибель, 
герой ценой жизни осуществляет прорыв в высшие сферы, своим примером показывая торжество моральных и духовных идеалов над смертью [9].

В музыке тип оптимистической трагедии в симфонизме был разработан Д.Д. Шостаковичем. Так, например, Д.Д. Шостаковичем тема рока трактуется по-иному, за исключением Седьмой симфонии, чем тема рока в симфониях П.И. Чайковского, где рок вторгается извне и все сметает на своем пути. В симфониях Д.Д. Шостаковича трагедия кроется внутри самой личности, где низменное в результате борьбы низвергается духовным. Для Д.Д. Шостаковича подлинная трагедийность не имеет ничего общего с пессимизмом: содержание современной трагедии «должно быть пронизано положительной идеей, подобно, например, жизнеутверждающему пафосу шекспировских трагедий» [5, с. 41].

Четырнадцатая симфония Д.Д. Шостаковича («Лики смерти»), написанная им в 1969 г. на стихи Е.А. Евтушенко под влиянием «Песен и плясок смерти» Мусоргского, которые Д.Д. Шостакович оркестровал семью годами ранее, была выражением отношения композитора к смерти: «Мне пришло в голову, что существуют вечные темы, вечные проблемы. Среди них - любовь и смерть. Вопросам любви я уделил внимание хотя бы в «Крейцеровой сонате» [из цикла «Сатиры»] на слова Саши Черного. Вопросами смерти я не занимался $<\ldots>$, я прослушал «Песни и пляски смерти» Мусоргского, и мысль заняться смертью созрела у меня окончательно» [3, с. 252]. Содержание Четырнадцатой симфонии Д.Д. Шостаковича составляют «вечные темы»- любви, жизни, смерти. Музыка пропитана философией трагизма. Противопоставляя в качестве контраста образ смерти, композитор стремится еще раз подчеркнуть, что жизнь прекрасна.

Сочинения последних десятилетий принадлежат к числу сложнейших партитур современного письма, вобравшего в себя самые разнообразные технические средства и приемы композиции. Одним из часто используемых композиторами средств в раскрытии драматургического замысла служит полистилистика. Авторы активно пользуются всеми ресурсами современного музыкального мышления, сплавляя старое и новое в органическом единстве. Часто при создании драматических образов внимание акцентируется преимущественно на современных средствах музыкального письма: 
элементах серийной техники, сонорных эффектах (кластер, хоровой шепот), микрополифонии, полиритмии, разнотембровых сочетаниях [9].

В романе В. Орлова «Альтист Данилов» [7] трагичное просматривается в новом направлении под названием «тишизма». Здесь нет бури, натиска, испепеляющей силы и т.п. Трагедия разворачивается в полной тишине, как это часто бывает в реальной жизни. И трагический разворот судьбы, и смерть одного из героев романа, отчаявшегося достигнуть совершенства в исполнении «звучащей» музыки и не нашедшего для себя выхода в «тишизме», является демонстрацией тихой трагедии. Феномен смерти в музыке трансформируется здесь в смерть самой музыки, которая, перестав звучать, исчезает как искусство.

Известный украинский композитор, или как его еще называют «живой классик», Валентин Сильвестров также в ходе эволюции своего творчества пришел к выражению трагедии в «тихой» музыке. Он напрямую связывает страдание и музыку: «Музыка - такой вид искусства, что если нет оттенка печали или сквозящей грусти, то нет и музыки. Причём печаль может быть разная - тёмная или светлая. Само занятие музыкой свойство лирического поэта. Грусть не оттого, что тяжелая жизнь, а потому, что музыка - это как ускользающая красота. Все мы, кто живёт на этом свете, вроде бы и радостные, но недолговечные. Остаётся только музыка» [1].

Кармелла Цепколенко в своем восприятии трагедийности ближе стоит к Шостаковичу, чем к Чайковскому или Сильвестрову. Она также делает акцент на трагедийности в своих симфониях и фортепианных концертах, по-особому, в присущей только ей манере, разворачивая материал в русле драматических коллизий театрализованной симфонизации концертного жанра. Остановимся подробнее на основных линиях развития трагедийности Концерта-Драмы № 2 для фортепиано, солистов и оркестра. Концерт написан в 2014 году, навеянный трагическими событиями Революции Достоинства. Как утверждает композитор, концерт писался по заранее продуманному сценарному плану, который существует, но остался только в сознании композитора и не был предан огласке [8, с. 13-14].

Как известно, в современной музыке произошла историческая смена парадигм: начало было положено в начале 
$\mathrm{XX}$ века с изобретением атональности, когда мелодия стала базироваться на 12 ступенях «нового» лада, в результате появилась додекафония, которая строилась на новых принципах - серийной системе. Вслед за материалом меняется и статус композиторской формы [8, с. 14]. Как отмечает Ю. Холопов, «особое значение здесь приобретает открытие третьего измерения музыки (помимо горизонтали-мелодии и вертикали-гармонии) - глубинной структуры музыкальной композиции, места развития многопараметровости <... Для каждого произведения композитор сочиняет вместе с материалом свою особую форму, тем самым отказываясь от векового принципа типовой формы: вместо формы-типа теперь создается не тип, а индивидуальный проект вещи» [10, с. 141].

Следуя принципам новых парадигм в современной музыкальной эстетике, К.С. Цепколенко выстраивает партитуру концерта-драмы по форме и структуре индивидуального проекта. Она, как и большинство современных композиторов, создает индивидуальную форму, адекватную архитектонике произведения и логике разворачивания трагико-драматических событий. Как отмечает композитор, «мои средства выражения отражают мои же ощущения, желания, устремления. Если мне не хватает известных знаков, я придумываю собственные и эти условные обозначения расшифровываю в приложении к произведению» [4, с. 219].

Концерт монотематичен - в пяти частях концерта разрабатывается музыкальный материал, который экспонируется в первой части. Все части идут без перерыва. Драматизация, трагедийный накал событий происходит за счет диалога солистов и оркестровых групп. Для осуществления своей идеи композитор создает настоящий инструментальный театр, где действие разворачивается по законам театральной логики с прологом, диалогами, массовыми сценами и пятью действиями. Композитор отказалась от традиционной сонатной формы в первой части, и форма каждой части строится как комплекс саморазворачивающихся событий.

Одной из особенностей творческого стиля К.С. Цепколенко есть склонность к гиперболизированным формам, в которых задействовано множество «персонажей» и параллельно развивается множество драматургических линий. Одним из самых крупных произведений в этом плане, своеобразной гиперструктурой можно считать международный 
фестиваль современного искусства «Два дня и две ночи новой музыки», который длится уже на протяжении 26-ти лет, где композитор является автором идеи и режиссером, который выстраивает 48-й часовой фестиваль по законам музыкальной драмы [2, с. 11].

Как отмечает композитор, современная музыка, отказавшись в своей основе от песенной формы развития, которая тысячелетиями главенствовала в сознании и стереотипах людей, ознаменовала рождение новой музыкально-эстетической парадигмы музыки, основанной на других принципах и формах развития. Рождение новой эры происходит, как это всегда бывает, сложно и болезненно. Композиторы ищут новые эстетические модели, создают теории, изобретают новые формы нотописи и т.п. вовсе не потому, что хотят чем-то удивить публику, а потому, что они уже вступили в новую эру, в которой не существует типовых форм, привычных стереотипов, квадратности, песенности, мелодии. Музыка становится многопластной, моногопараметровой, и каждый композитор стремится создать не тип, а индивидуальный проект произведения. В современном мире композиторы сочиняют не только отдельные произведения, но и создают мегаструктуры - фестивали современной музыки, где в качестве материала используют произведения других композиторов, размещая их по законам современной концепции формотворчества и современного мироощущения [6].

Рассматривая с этих позиций Второй концерт, нельзя не отметить, что он входит в открытую концертную гиперструктуру, которая состоит уже из двух концертов, где второй является как бы продолжением первого концерта, и открыта для дальнейшего развития.

Объединяющим моментом двух концертов, кроме названия, есть идея 5-ти каденций, с той только разницей что в первом концерте каденции для фортепиано соло, здесь те же 5 каденций, но в них, кроме фортепиано, участвует еще и один из солистов (первая каденция фортепиано+перкуссия, вторая каденция - фортепиано и скрипка, третья каденция - фортепиано и труба, четвертая каденция - фортепиано и кларнет, пятая каденция для всех, кто участвовал в предыдущих каденциях, - фортепиано, кларнет, труба, ударные, скрипка. Трагическое нагнетание и драматическое развитие происходит за счет диалога солистов и оркестровых групп. 
Если в первом концерте-драме каденции являлись, с одной стороны, как бы связующими элементами в глобальном акте театрализации, с другой - этапами развития и страдания героя, то здесь каденции являются средством диалогического драматического развития, которое применяется в каждой из частей. Сами каденции появляются более традиционно в конце частей, кроме четвертой, где каденция в середине части, и пятой части, где каденция звучит в самом начале.

Начинается концерт своеобразным прологом. Тремолирующий аккорд в divisi у струнных, появившись, быстро затухает и превращается в педальный фон, на основе которого появляются небольшие ритмические фигуры у ударных (маримба, 4 тома, темпельблок и тарелка). Это первые элементы тематического материала, это как бы первая экспозиция действующих лиц с небольшими репликами. Заканчивает эту фигуру аккорд у всего дерева на синкопирующей доле. Снимается педаль у струнных - пролог закончен. Следующий важный элемент, который будет разрабатываться на протяжении всех пяти частей, возникает у соло фортепиано - четыре шестнадцатые, разбросанные в позиции двух октав и заканчивающиеся длинной нотой. Этот элемент повторяется дважды в развитии как призывный жест. Это своеобразная реплика, обращающая на себя внимание эпатажностью, броскостью. Вся эта структура представляет собой первый комплекс, который повторяется еще три раза (ц. 1-4), постепенно развиваясь, увеличиваясь в объеме, и завершается небольшой кульминацией.

Следующий раздел представляет собой контраст по сравнению со вступлением, и поначалу возникает ощущение спокойствия и меланхолии. Как отмечает Ю. Холопов, «в музыке Авангарда-II около середины XX века происходит важнейшее событие: вытеснение из структуры произведения песенной формы с ее «природным» кристаллом ритма строк и каденций формы, еще хранившей историческую память о первородном триединстве музыки, поэзии (в ней тоже строфа-кристалл) и танца (в нем та же симметрия телесного ритма). Во всех единично-индивидуальных замыслах произведений устраняется красота слаженной песенной формы, что и знаменует собой коренную смену главнейшей музыкально-эстетической парадигмы музыки. В частности, устраняется «мусическая» песенная структура, основа классического тематизма (представим 
себе: все главные темы в каждой форме каждой классической симфонии, каждого концерта, каждой сонаты, каждой кантаты, каждой оперной арии, похоронного или военного марша, каждого танца на танцплощадке и т. д. - все они основываются на одном и том же «мусическом» типе песенной формы; и вдруг эта парадигма, основа основ, исчезла) [10, с. 141].

Рассматривая мелодику второго раздела, нужно учитывать эту историческую смену парадигм - это длинные звуки у четырех валторн и синкопирующие короткие звуки-капельки (пиццикато струнных и маримба).

Постепенно напряжение возрастает, это достигается серией структурных наслоений, в которые постепенно вовлекается весь оркестр. Драматизм ситуации достигается тем, что большое фактурное накопление внезапно обрывается аккордом у фортепиано вместе с литаврами, томом и темпльблоком. Начинается первая каденция, которая представляет собой дуэт фортепиано и ударных (литавры, 4 томтома, 4 темпльблока). Здесь намечается первое драматическое противостояние личности и враждебно настроенной среды. Каденция без перерыва въезжает во вторую часть. В классической схеме, как правило, вторая часть - спокойная, события разворачиваются в ней медленно, степенно, звуковая ткань насыщена размышлениями, выражает картины природы и т.п. К.С. Цепколенко нарушает этот принцип. Вторая часть, вопреки традиционным построениям, не приносит успокоения и продолжает драматическое нагнетание. Чередующиеся звуковые наслоения фактуры приводят все построение к кульминации, которая достигается за счет ударных и духовых инструментов, без участия струнных.

На вершине кульминации подключаются литавры, тарелки и большой барабан, создавая впечатление катастрофы, разрушения, ужаса и страдания. Три волны, одна за другой, постепенно затухая, приводят ко второй каденции (фортепиано и скрипка), которая строится на элементе из трижды повторенных шестнадцатых, разбросанных в позиции двух октав у фортепиано (из первой части). Гаммообразное моторное движение шестнадцатыми у фортепиано пронизывает всю каденцию. В ходе диалогического взаимодействия шестнадцатые постепенно проникают в фактуру скрипки, затем элементы фактуры скрипичной партии перетекают снова к фортепиано. Bсе это происходит в быстром моторном ритме, в фактур- 
ных накоплениях. Здесь можно себе представить, что первая трагедийная кульминация наступила, но, несмотря на огромные потери, сопротивление не сломлено, и оставшиеся силы быстро перегруппировываются, обмениваясь друг с другом необходимым инвентарем. Постепенно дует скрипки и фортепиано обретает силу, появляются призывные мотивы, усиливается динамика и заканчивается эпизод кульминационным построением, которое неожиданно прерывается небольшим призывным соло, как криком о помощи, являющимся своеобразным мостиком к третьей части.

В третьей части композитор использует один из своих любимых приемов - густое фактурное наслоение, одновременное линеарное звучание всех пластов, диалогические реплики между группами инструментов. Волна за волной нагнетается напряженность. Первый кульминационный всплеск завершается тремоло маримбы, вторая волна (ц. 20) по протяженности несколько длиннее (длится 8 тактов). Третья волна возникает после перебивки валторн на длинной ноте и двух труб с отрывистыми сигнальными тонами (ц. 21), после чего начинается диалог между фортепиано и трубой. Противостояние усиливается. Труба призывает к действию, короткие восходящие мотивы раз за разом обрастают фактурными наслоениями фортепиано, которые характеризуются широким движением шестнадцатыми, которое длится сначала с небольшими перерывами, а затем перерастает в сплошное движение. Постепенно к дуэту подсоединяются другие инструменты, с каждым волнообразным оборотом фактура насыщается и усложняется. По характеру участия всех инструментальных групп в массовом диалоге этот эпизод можно сравнить с драматическим действием, когда неотвратимая цепь событий сводит всех действующих лиц вместе. Постепенно напряжение спадает, и оркестр, который участвует в диалоге отдельными группами, выходит из игры: сначала постепенно отключаются струнные и деревянные духовые, затем медные инструменты, и все замирает на длинной ноте у трубы.

Начинается третья каденция - фортепиано и труба. Каденция строится на материале небольшого диалога между первой трубой и фортепиано из предыдущей части. Здесь материал получает виртуозное развитие и становится смысловой кульминацией части. Четвертая часть также начинается без 
перерыва. Содержательная часть строится на базе двух тематических комплексов: сигнального элемента медных (ц. 29) и тремоло у большого барабана на пиано (ц. 30). Происходит постепенное сближение позиций разных групп оркестра: сначала каждая из групп вступает через 5 тактов, затем 4, 3, 2 и, наконец, все вместе. Все это приводит к кульминации, которая обрывается четвертой каденцией, возникающей в середине части соло кларнета. Фортепиано вступает в диалог робко, очень деликатно и нежно, вся эта каденция представляет собой идиллию общения. Возникает иллюзия того, что трагическая ситуация может разрешиться мирно. Это подчеркивается и скерцозностью, которая поочередно возникает у разных групп оркестра. Однако ощущение некоторой игривости и легкости постепенно сменяется алеаторическими фигурами, что приводит к динамическому нарастанию. В кульминации вступают триольные фигуры у медных инструментов, которые переходят в устрашающие глиссандирующие пассажи всех медных инструментов, наводя ужас и страх. Постепенно кульминация идет на спад, и на длинных нотах остаются только те инструменты, которые будет участвовать в последней каденции. Так начинается Пятая часть. После всех ужасов трагедии предыдущих частей остается кларнет, труба, фортепиано, скрипка и ударные. Это итог ужасной, опустошающей трагедии. У всех духовых длинные ноты, фортепиано держит кластер, ударные тремоло - на пианиссимо. Последняя каденция построена как диалог всех участников предыдущих каденций, где каждый исполняет структурные элементы своих тем. Постепенно жизнь возвращается, и оставшиеся инструменты пытаются восстанавливать отношения. На 52 ц., подключаясь к созидательной программе, вступает весь оркестр на материале аккорда у деревянных духовых и divisi струнных из начала первой части. Затем проходят фрагменты из первого комплекса четвертой части + элементы из каденции секстолями у фортепиано и ударных. Вся эта структура повторяется трижды. На третий раз, во время очередного вступления всего оркестра, синкопой вступают медь и фортепиано, все держится на форте, пока у фортепиано не возникает «разбитый» фактурный элемент из первой части - шестнадцатые в разбросе двух октав. Каждое проведение этого элемента включает из игры одну из групп оркестра: первый раз замолкают медные инструменты, затем ударные, деревянные духо- 
вые и, наконец, струнные. Так завершается концерт. Финал концерта звучит жизнеутверждающе. Все ужасное прошло, и трагедийность предыдущих событий подчеркнула красоту жизни во всей ее гармонии и красоте.

Выводы. В своем фортепианном концерте композитор экспериментирует, изобретает новую технику, разрабатывает оригинальные формы, основанные на новых представлениях и ощущениях конкретного времени, где главными событийными моментами становится музыкальная объемность и театральная насыщенность. Основными принципами, на которых строится драматургия концерта, являются противопоставления трагедийности и лирики; многотемность и разнообразие развивающих приёмов; многообразие стилевых истоков и жанровая диффузность (свободное, естественное сочетание разных «лексик»).

Композитор выстраивает структуру концерта из множества контрастных, подчас «полярных» по природе эпизодов, тем, мотивов, интонаций, объединяя их симфоническими принципами развития, что придает произведению естественность, многогранность и подтекстовую многозначность.

\section{СПИСОК ЛИТЕРАТУРЫ}

1. Вареник Н.В. «Частный» человек Валентин Сильвестров: «Музыка - как ускользающая красота». 2007. URL: http://www. litsovet.ru/index.php/material.read?material_id=138011 (дата обращения: 14.09.2020).

2. Два дні й дві ночі нової музики : міжнародний фестиваль сучасного мистецтва 1995-2019 : альбом-книга, присвячена 25-річниці фестивалю / керівник проекту та автор програм фестивалю Кармелла Цепколенко ; упорядник та головний редактор Олександр Перепелиця. Одеса : «Асоціація «Нова музика», 2018. 504 с.

3. Лобанова М.Н. Западноевропейское музыкальное барокко: проблемы эстетики и поэтики : монография. Москва : Музыка, 1994. $322 \mathrm{c}$.

4. Лунина А. Композитор в зеркале современности : в 2 т. Киев : Дух і Літера, 2015. Т. 2. 472 с.

5. Мазель Л. Симфонии Д.Д. Шостаковича. Москва : Советский композитор, $1960.150 \mathrm{c}$.

6. Олейник Л. Мы все равно победим... : интервью с Кармеллой Цепколенко. День. 2015. № 43. 13 марта. URL: http://m.day.kyiv.ua/ $\mathrm{ru} /$ article/kultura/my-vse-ravno-pobedim (дата обращения: 14.09.2020).

7. Орлов В. Альтист Данилов. Москва : АСТ, 2002. 421 с.

8. Перепелица М.Ю. Театральность как форма развития драматургии фортепианных концертов Кармеллы Цепколенко. Наукові 
записки Тернопільського національного педагогічного університету імені Володимира Гнатюка. Серія: Мистеитвознавство ; за ред. О.С. Смолюка. Тернопіль, 2015. № 1. Вип. 33. С. 9-19.

9. Уваров М.С. Смерть и погребение в музыке. Альманах «Фигуры Танатоса», Кладбище. Санкт-Петербург : Изд-во Института Человека РАН (СПб Отделение), 2001. Вып. 6. URL: http://anthropology. $\mathrm{ru} / \mathrm{ru} / \mathrm{text} / \mathrm{uvarov}-\mathrm{ms} / \mathrm{smert}-\mathrm{i}$-pogrebenie-v-muzyke (дата обращения: 14.09.2020).

10. Холопов Ю.Н. Новые парадигмы музыкальной эстетики XX века. Эстетика на переломе культурных традиций. Москва : ИФ PAH, 2002. C. 132-147.

\section{REFERENCES}

1. Varenik N. V. (2007) "Chastnyy" chelovek Valentin Sil'vestrov: "Muzyka - kak uskol'zayushchaya krasota". ["Private" person Valentin Silvestrov: "Music is like elusive beauty"]. Retrieved from: http://www. litsovet.ru/index.php/material.read?material_id=138011 (Accessed 14 September 2020).

2. Lobanova M. N. (1994) "Zapadnoyevropeyskoye muzykal'noye barokko: problemy estetiki i poetiki". Monografiya. ["Western European musical baroque: problems of aesthetics and poetics". Monograph] Moscow : Music, -322 p. (in Russian).

3. Lunina A. (2015) "Kompozitor v zerkale sovremennosti”. V 2-kh tomakh. T. 2. ["Composer in the Mirror of Modernity". In 2 volumes. V. 2.] - Kiev: Spirit and Litera, -472 p. (in Russian).

4. Mazel L. (1960) "Simfonii D. D. Shostakovicha". ["Symphonies by D. D. Shostakovich"]. Moscow : Soviet composer,. 150 p. (in Russian).

5. Oleinik L. S. (2015) "My vse ravno pobedim..." : interv'yu s Karmelloy Tsepkolenko. ["We will win anyway ...": interview with Karmella Tsepkolenko] // Electronic newspaper Day, № 43, 13 March 2015. Retrieved from: - http://m.day.kyiv.ua/ru/article/kultura/my-vse-ravnopobedim, (Accessed 14 September 2020).

6. Orlov V. (2002) "Al'tist Danilov". ["Violinist Danilov"]. Moscow : AST publishing house, -421 p. (in Russian)

7. Perepelytsia M. Yu. (2015). "Teatral'nost' kak forma razvitiya dramaturgii fortepiannykh kontsertov Karmelly Tsepkolenko" ["Theatricality as a Form of Development of the Dramaturgy of the Piano Concertos by Karmella Tsepkolenko"]. Naukovi zapysky Ternopil's'koho natsional'noho pedahohichnoho universytetu imeni Volodymyra Hnatyuka. Seriya: Mistetstvoznavstvo. [Scholarly Notes of the Volodymyr Hnatiuk Ternopil National Pedagogical University. Series: Art Studies]. Ed. O. S. Smolyuk. Ternopil, No. 1, Issue 33, pp. 9-19.

8. Perepelytsia O. (2018) "Dva dni y dvi nochi novoyi muzyky: mizhnarodnyy festyval' suchasnoho mystetstva 1995-2019: al'bom-knyha, prysvyachena 25-richnytsi festyvalyu". Kerivnyk proektu ta avtor prohram festyvalyu Karmella Tsepkolenko; uporyadnyk ta holovnyy redaktor Oleksandr Perepelytsia. ["Two Days and Two Nights of New Music: 
International Festival of Contemporary Art 1995-2019: album-book dedicated to the 25th anniversary of the festival". Project manager and author of festival programs Karmella Tsepkolenko; compiler and editorin-chief Oleksandr Perepelytsia]. Odessa: New Music Association, 504 p. (in Ukrainian and English).

9. Uvarov M. S. (2001). "Smert' i pogrebeniye v muzyke". ["Death and burial in music"] // Al'manakh "Figury Tanatosa", Kladbishche, Vyp. 6. - Sankt-Peterburg: Izd-vo Instituta Cheloveka RAN (SPb Otdeleniye, [Almanac "Figures of Thanatos", Cemetery., Issue 6. St. Petersburg: Publishing house of the Institute of Man of the Russian Academy of Sciences (St. Petersburg Branch)] - Retrieved from: http:// anthropology.ru/ru/text/uvarov-ms/smert-i-pogrebenie-v-muzyke (accessed 14 September 2020).

10. Kholopov Yu. N. (2002) "Novyye paradigmy muzykal'noy estetiki XX veka. Estetika na perelome kul'turnykh traditsiy". ["New paradigms of musical aesthetics of the XX century. Aesthetics at the turning point of cultural traditions"]. Moscow : IF RAN, 2002. - P. 132-147.

УДК 7.035(477)(045)

DOI https://doi.org/10.31723/2524-0447-2020-30-2-18

\section{Тетяна Петрівна Сухомлінова}

ORCID: 0000-0002-7251-0793

кандидат мистецтвознавства,

старший викладач кафедри хорового диригування та академічного співу

Харківської державної академії культури,

викладач вищої категорії предметно-циклової комісії «Хорове диригування» Харківського музичного училища імені Б. М. Лятошинського sukhomlinova.tetyana@gmail.com

\section{ПЕРІОДИЗАЦІЯ УКРАЇНСЬКОГО ВІДРОДЖЕННЯ: ІСТОРИКО-КУЛЬТОРОЛОГІЧНИЙ ПІДХІД}

Мета роботи виокремити ренесансні за суттю періоди в історіі української художньооі культури від Київської Русі до ХХ століття. Методологія дослідження полягає у застосуванні принципу історизму, що впроваджується для виявлення періодів ренесансного змісту в історії

(C) Сухомлінова Т. П., 2020 